\title{
Biocatalytic potential of vanillin aminotransferase from Capsicum chinense
}

\author{
Nora Weber ${ }^{1}$, Abdelrahman Ismail ${ }^{2}$, Marie Gorwa-Grauslund ${ }^{1}$ and Magnus Carlquist ${ }^{1 *}$
}

\begin{abstract}
Background: The conversion of vanillin to vanillylamine is a key step in the biosynthetic route towards capsaicinoids in pungent cultivars of Capsicum sp. The reaction has previously been annotated to be catalysed by PAMT (putative aminotransferase; [GenBank: AAC78480.1, Swiss-Prot: O82521]), however, the enzyme has previously not been biochemically characterised in vitro.

Results: The biochemical activity of the transaminase was confirmed by direct measurement of the reaction with purified recombinant enzyme. The enzyme accepted pyruvate, and oxaloacetate but not 2-oxoglutarate as co-substrate, which is in accordance with other characterised transaminases from the plant kingdom. The enzyme was also able to convert (S)-1-phenylethylamine into acetophenone with high stereo-selectivity. Additionally, it was shown to be active at a broad $\mathrm{pH}$ range.

Conclusions: We suggest PAMT to be renamed to VAMT (vanillin aminotransferase, abbreviation used in this study) as formation of vanillin from vanillylamine could be demonstrated. Furthermore, due to high stereoselectivity and activity at physiological pH, VAMT is a suitable candidate for biocatalytic transamination in a recombinant whole-cell system.
\end{abstract}

Keywords: Putative aminotransferase, PAMT, VAMT, Transaminase, Vanillylamine, 1-phenylethylamine, Acetophenone, Whole-cell biocatalysis, Capsaicinoids

\section{Background}

Chili pepper fruit (Capsicum sp.) gives rise to a strong pungent sensation when eaten, due to the presence of capsaicinoids, with capsaicin (trans-8-methyl- $N$-vanillyl-6nonenamide) as the most known example [1]. Capsaicinoids have been considered as anti-obesity, antimicrobial and antineoplastic agents [1,2], and for the prevention of hypertension [3]. Additionally, capsaicin is a very potent agonist of the pain receptor TRPV1 $[4,5]$ and is therefore used as a therapeutic drug in the treatment of peripheral neuropathy. Since the discovery of capsaicinoids there has been substantial amount of research dedicated to the understanding of biosynthetic pathways leading to capsaicinoids in different cultivars of Capsicum sp. Although the biochemical pathways leading to capsaicin are described, there is still a knowledge-gap with regards to the identity

\footnotetext{
* Correspondence: magnus.carlquist@tmb.lth.se

'Division of Applied Microbiology, Department of Chemistry, Lund University, SE-22100 Lund, Sweden

Full list of author information is available at the end of the article
}

of some of the involved enzymes (cf. review by AzaGonzález et al. [2]).

In brief, capsaicin synthesis in Capsicum sp. is achieved through combination of two separate pathways, namely: (i) phenylalanine conversion to vanillylamine; and (ii) valine conversion to 8-methyl-6-nonenyl-CoA acid via the fatty acid metabolism. The two pathways are connected in a capsaicinoid synthase-catalysed condensation reaction between vanillylamine and 8-methyl-6-nonenyl-CoA to form capsaicin [2]. A key step in the biosynthetic route to capsaicin is the conversion of vanillin to vanillylamine via transamination of the aldehyde moiety into the corresponding amine [6] (Figure 1). The responsible enzyme for transamination of vanillin has previously been addressed to be putative aminotransferase (PAMT) [GenBank: AAC78480.1, Swiss-Prot: O82521] [7]. Although functional studies in vivo clearly indicate that PAMT is responsible for the transamination of vanillin in Capsicum sp. $[6,8]$, the pure enzyme has, to the best of our knowledge, not been characterised in vitro.

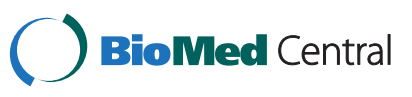

(c) 2014 Weber et al.; licensee BioMed Central Ltd. This is an Open Access article distributed under the terms of the Creative Commons Attribution License (http://creativecommons.org/licenses/by/2.0), which permits unrestricted use, distribution, and reproduction in any medium, provided the original work is properly credited. 


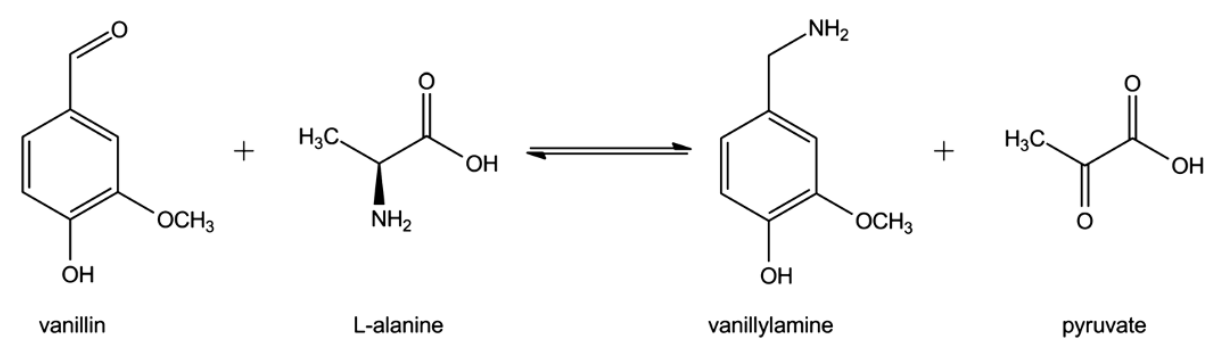

Figure 1 Transamination of vanillin to vanillylamine with L-alanine as amine donor, catalysed by vanillin transaminase (VAMT).

In this study, the gene encoding PAMT was functionally expressed in Escherichia coli and the polyhistidine-tagged enzyme was purified to homogeneity using affinity chromatography and subsequently characterised. It is confirmed that PAMT converts vanillylamine to vanillin, and should therefore from now on be called "vanillin aminotransferase (VAMT)". The enzyme can also be used for the kinetic resolution of racemic 1-phenylethylamine to (R)-1-phenylethylamine and acetophenone, and thus carries the potential to be applied for biocatalytic transamination for the preparation of chiral amines.

\section{Results and discussion}

\section{Cloning, expression and purification of VAMT}

Codon-optimised synthetic $C$. chinense VAMT gene was cloned into an E. coli expression vector downstream of the IPTG-inducible T7 promoter, resulting in plasmid pNW1 (Table 1). The plasmid was used to transform $E$. coli BL21, generating strain TMB2100 (Table 1). At first the expression of the protein was investigated with induction at optimal temperature for $E$. coli growth $\left(37^{\circ} \mathrm{C}\right)$, however, no enzyme activity in cell free lysate could be registered. Possible explanations include the formation of inclusion bodies or other incorrect folding of the recombinant protein as previously observed for other systems [9]. To solve this problem, a lower temperature $\left(15^{\circ} \mathrm{C}\right)$ for the protein induction-expression step was chosen, which led to a high expression of the active enzyme. The polyhistidine-tagged protein was purified from cell free lysate using affinity chromatography, and no contaminating proteins could be detected by SDS-PAGE analysis of the purified enzyme solution (Figure 2).

Functional validation of vanillin aminotransferase activity Most known transaminases of both bacterial and plant origin accept L-alanine as amine donor [10-15]. The purified enzyme was therefore first evaluated for the conversion of vanillin to vanillylamine with a high excess of alanine as amine donor. It was, however, not possible to detect any formation of vanillylamine. Conversion was neither observed with the following amine donors: D-alanine, GABA, glutamine and ornithine. However it cannot be excluded that some vanillylamine (below the detection limit of our HPLC analysis) was formed since transamination of a small amount of vanillin was previously observed in crude cell extract from pungent pepper Capsicum annuum and with GABA as amine donor [6]. However, the Gibbs free energy of the reaction, $\Delta G 0$ ', as calculated by using the group contribution method [16], was $\Delta G 0^{\prime}=+2.55 \mathrm{kcal} / \mathrm{mol}$ when using Lalanine and other amino acids as amine donor. The reaction was consequently thermodynamically favouring the reverse reaction and a high conversion of vanillin was, even with an excess addition of the amine donor, not expectable. It has previously been shown for other transaminases that a (co-) product removal system was required to reach conversion of aromatic ketones to amines $[12,17,18]$. Therefore, the enzyme was instead evaluated for the conversion of vanillylamine to vanillin using pyruvate as amine acceptor. In this case, the

Table 1 Strains and plasmids used in this study

\begin{tabular}{lll}
\hline Strains and plasmids & Relevant phenotype & Reference \\
\hline Plasmids & & GenScript, NJ, USA \\
pUC 57 VAMT & Gene for VAMT & Invitrogen, CA, USA \\
pRSETB & Plasmid with T7 promotor and terminator, Amp resistance gene & This study \\
pNW1 & VAMT under T7 promoter, with T7 terminator, Amp resistance gene & Life Technologies, MD, USA \\
Strains & & Invitrogen, CA, USA \\
E. coli DH5a & & This study \\
E. coli BL21(DE3) pLys & E. coli BL21, containing pNW1 & \\
E. coli TMB2100 &
\end{tabular}




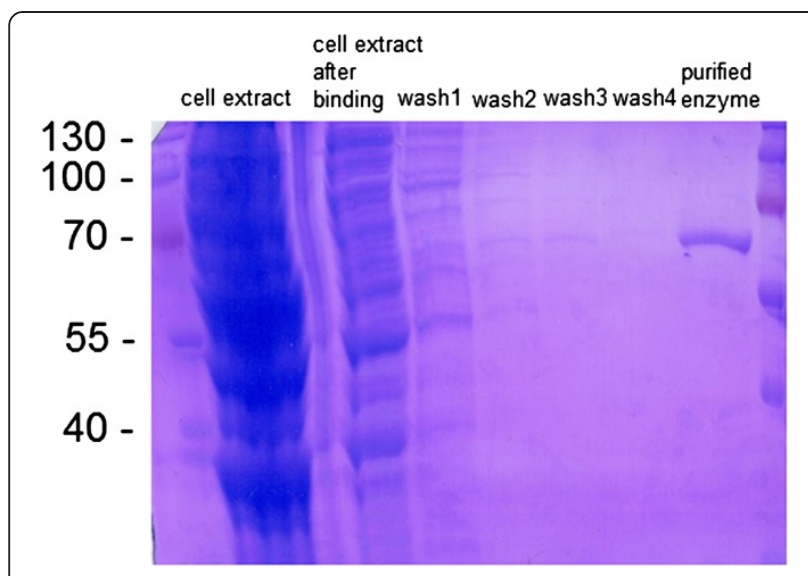

Figure 2 SDS-PAGE analysis of cell extract, purification steps and purified VAMT. Molecular size of VAMT with His-tag: 57.5 kDa.

formation of vanillin could be detected shortly after the start of the reaction (the specific activity of the enzyme was approximately $5 \mathrm{U} / \mathrm{mg}$ protein), which indicates that VAMT indeed is responsible for vanillylamine formation in $C$. chinense. Whether this activity can be found in orthologous plant transaminases and is a general trait, or if it is a specific natural function of VAMT that has been evolved over time, is unknown. BlastP search within the NCBI database (http://blast.ncbi.nlm.nih.gov/ Blast.cgi) with the amino acid sequence of VAMT identified $\gamma$-aminobutyrate (GABA) transaminases, catalysing the conversion of GABA to succinate semialdehyde as the most similar enzymes. The amino acid sequence of VAMT notably shared $76-83 \%$ identity to known plant GABA transaminases originating from Arabidopsis thaliana [10], apple [15] and tomato [11]. None of these enzymes have been investigated for the ability to convert vanillin or vanillylamine. In fact, transamination of vanillin has, to the best of our knowledge, only been reported for the $\omega$-transaminase from Chromobacterium violaceum DSM 30191 (CV- $\omega$ TA) [13]; however, transamination of numerous aryl substituted aldehydes and ketones have previously been described for $\omega$-transaminases originating from various soil-living bacteria, for example $\omega$-TAs from Aspergillus terreus, Hyphomonas neptunium, and Arthrobacter ATA-117 [14,19]. It is likely that there are several other transaminases unrelated to VAMT that are able to convert vanillin to vanillylamine.

\section{Potential for biocatalytic transaminations}

To evaluate whether VAMT has any potential for biocatalytic transamination for the preparation of chiral amines, kinetic resolution of ( $\mathrm{rac}$ )-1-phenylethylamine (1-PEA) was examined and which enantiomeric selectivity the enzyme possesses. The kinetic resolution of $(\mathrm{rac})$ 1-PEA using pyruvate as amine acceptor was initiated by addition of the enzyme and was allowed to continue for
24 hours. The products were extracted with heptane and analysed using chiral HPLC. (S)-1-PEA was fully converted into acetophenone, while (R)-1-PEA remained, leading to an ee $>99 \%$ at $50 \%$ conversion of (rac)-1-PEA. Alike VAMT, most known transaminases that have been used for the generation of chiral amines are $S$-selective [14], with a few exceptions of $R$-selective enzymes [20,21].

To investigate which co-substrates were accepted by VAMT, kinetic resolution with different amine acceptors was carried out (Figure 3). In addition to pyruvate, it was shown that oxaloacetate was also accepted as co-substrate by the enzyme. The enzyme was not able to use 2oxoglutarate as amine acceptor, which is in accordance with other known GABA transaminases of plant origin $[10,11,15]$; nor was it able to use succinate or acetone as amine acceptor. However the aromatic aldehyde $p$-hydroxybenzaldehyde displayed some reactivity.

The optimal $\mathrm{pH}$ for VAMT activity was investigated by following the relative conversion of (S)-1-phenylethylamine to acetophenone at different $\mathrm{pH}$ between 6 to 12 (Figure 4). Noteworthy, the enzyme displayed activity over a broad $\mathrm{pH}$ range ( $\mathrm{pH}$ 6-10), and had the highest activity at $\mathrm{pH} 7-8$, which is rather unique in comparison with several other transaminases that have a higher $\mathrm{pH}$ optimum [20,22-27]. The high activity at physiological $\mathrm{pH}$ demonstrates that VAMT is suitable for whole-cell transamination systems where the reaction takes place in the cytoplasm of viable and metabolically active cells.

\section{Conclusions}

For the first time, the catalytic activity of vanillin transaminase from chili pepper plant Capsicum chinense was demonstrated with the purified enzyme in vitro. The enzyme displayed high transaminase activity towards vanillylamine and (S)-1-phenylethylamine with pyruvate or oxaloacetate as amine acceptor, and the enzyme was

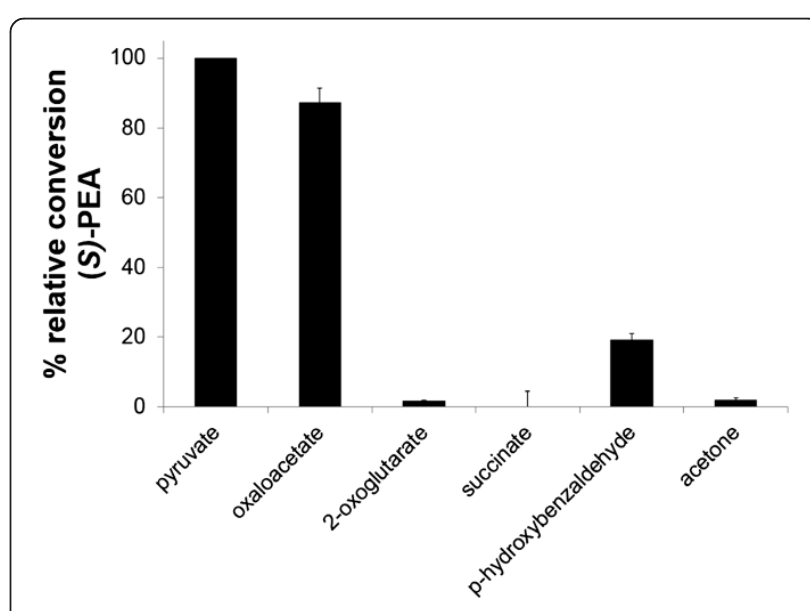

Figure 3 Relative conversion of (S)-1-phenylethylamine ((S)-1-PEA) with different amine acceptors. 


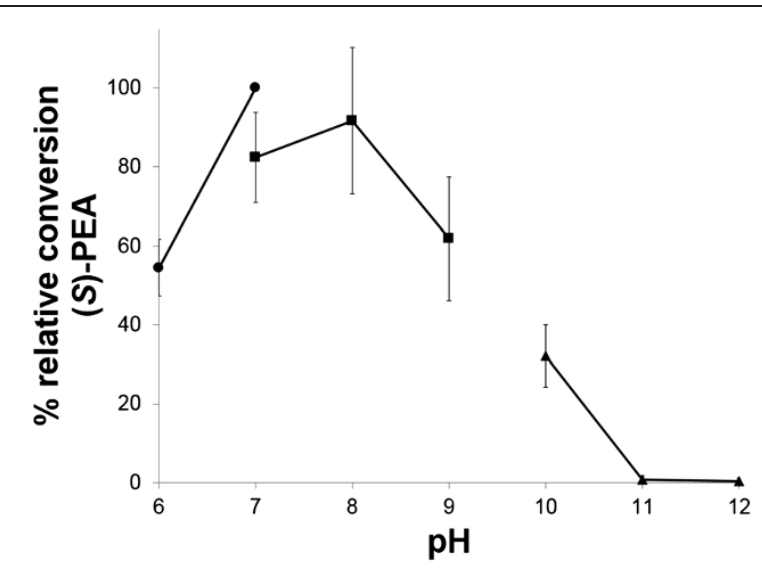

Figure 4 Relative conversion of (S)-1-phenylethylamine at different $\mathrm{pH}$ ranging from 6 to 12 . (•) Sodium phosphate buffer; (-) TRIS buffer; ( $\mathbf{\Delta}$ ) CAPS buffer.

active at a broad $\mathrm{pH}$ range. Thus, VAMT can be used for the preparation of chiral amines, and represents an interesting candidate to be used in whole-cell biocatalysis with recombinant microorganisms.

\section{Methods}

\section{Strains and cultivation conditions}

E. coli strains and plasmids used in the study are listed in Table 1. E. coli strain DH5 $\alpha$ was used for subcloning and transformants were selected on lysogeny broth (LB) media supplemented with $100 \mathrm{mg} / \mathrm{l}$ ampicillin (IBI Shelton Scientific, CT, USA). Strains were kept in $20 \% \mathrm{v} / \mathrm{v}$ glycerol stocks at $-80^{\circ} \mathrm{C}$ and grown for 1 day on $\mathrm{LB}$ plates at $37^{\circ} \mathrm{C}$ before use. A single colony was picked and pre-cultured overnight in LB media and used for subsequent inoculation.

\section{Strain construction}

Standard molecular biology techniques were used for all cloning procedures [28]. Plasmid DNA was prepared with the GeneJET ${ }^{\mathrm{m}}$ Plasmid Miniprep Kit (Fermentas UAB, Vilnius, Lithuania). Agarose gel DNA extraction was made with QIAquick ${ }^{\circ}$ Gel Extraction Kit (Qiagen GmbH, Hilden, Germany). Sequencing was performed by MWG-Biotech AG (Ebersberg, Germany). Restriction endonucleases and T4 DNA Ligase from Fermentas were used for DNA manipulation. Transformation of $E$. coli was performed with the calcium chloride [29] method.

The VAMT gene from C. chinense [GenBank: AAC78480.1, Swiss-Prot: O82521] was constructed synthetically (GenScript, NJ, USA), resulting in plasmid pUC57 VAMT (Table 1). The plasmid was digested with restriction enzymes BamHI and Pst , and the resulting fragment was inserted into pRSETB (Invitrogen, CA, USA). The resulting plasmid pNW1 was digested with BamHI, treated with Klenow fragment from Fermentas and re-ligated with T4 DNA Ligase from Fermentas to move the gene in frame. Correct orientations and sequences of the inserts were verified by restriction analysis and sequencing. pNW1 was transformed into E. coli BL21 (DE3) pLys which gave strain TMB2100.

\section{Cell growth}

A single microbial colony of TMB2100 from a LB plate [30] containing $100 \mathrm{mg} / \mathrm{l}$ ampicillin was inoculated in $50 \mathrm{ml} \mathrm{LB}$ medium containing $100 \mathrm{mg} / \mathrm{l}$ ampicillin. Cells were grown overnight (at least $16 \mathrm{hr}$ ) in an incubator at $37^{\circ} \mathrm{C}$ with shaking at $180 \mathrm{rpm}$. The preculture was used to inoculate $250 \mathrm{ml} \mathrm{LB}$ medium containing $100 \mathrm{mg} / \mathrm{l}$ ampicillin in a 11 shake flask with an optical density $\left(\mathrm{OD}_{620}\right)$ of 0.1 and growth was performed at $37^{\circ} \mathrm{C}$ and $180 \mathrm{rpm}$. Expression of the transaminase gene VAMT was induced by addition of isopropyl- $\beta$-D-thiogalactoside (IPTG) to a final concentration of $1 \mathrm{mM}$ when the $\mathrm{OD}_{620}$ of the culture reached 0.6 to 0.8 and incubation was then continued for 24 hours at $15^{\circ} \mathrm{C}$ and $180 \mathrm{rpm}$.

\section{Purification of the transaminase}

Cells of recombinant $E$. coli strain TMB2100 were harvested by centrifugation $(3200 \times g, 10 \mathrm{~min})$ and washed once with $25 \mathrm{~mL}$ water. The cell pellet was resuspended in equilibration buffer, according to the manufacturer's instructions, and subjected to sonication in a sonicator (Bandelin electronics, Berlin, Germany). Cell debris was removed by centrifugation $(3200 \times g, 10 \mathrm{~min})$. The clear lysate supernatant was collected and passed through a nickel column (HisPur ${ }^{\mathrm{Tu}}$ Ni-NTA Purification Kit, Thermo Scientific, Rockford, IL, USA), according to the description of the manufacturer. The purified transaminase was collected after elution with buffer, according to the manufacturer's instructions. Protein concentration was determined using the Bradford method with bovine serum albumin (BSA) as a standard [31]. Purity of the protein in the eluent was estimated with SDS-PAGE (Figure 2). The identity of the protein was confirmed by mass spectrometry at the SWEGENE proteomics platform (Lund, Sweden). The concentration of the purified transaminase was approximately $0.5 \mathrm{mg} / \mathrm{ml}$.

\section{Enzyme activity assay}

Purified VAMT $(0.5 \mathrm{ml})$ was mixed with $4 \mathrm{mM}$ vanillylamine, (rac)-1-phenylethylamine (1-PEA) or vanillin, PLP $(0.1 \mathrm{mM})$, and one of the following co-substrates $(40 \mathrm{mM}$ for amine acceptors, $100 \mathrm{mM}$ for amine donors): pyruvate, oxaloacetate, 2-oxoglutarate, succinate, $p$-hydroxybenzaldehyde, acetone, L-alanine, D-alanine, GABA, glutamine or ornithine. The reaction was performed in $1 \mathrm{ml}$ sodium phosphate buffer (100 mM, pH 6-7), Tris- $\mathrm{HCl}$ buffer (100 mM, pH 7-9) or CAPS buffer (100 mM, pH 10-12) in a glass vial. The reaction was started by the addition of the substrate and it was quenched by the addition of $0.1 \mathrm{ml}$ 
$1 \mathrm{M} \mathrm{HCl}$. Samples were kept at $-20^{\circ} \mathrm{C}$ until analysis. Thawing of samples $(0.5 \mathrm{ml})$ was done at room temperature and 1-PEA and acetophenone (ACP) were extracted with $0.6 \mathrm{ml}$ heptane, after addition of $30 \mu \mathrm{l} \mathrm{NaOH}(10 \mathrm{M})$, and analyzed by HPLC. The specific activity of the enzyme was calculated based on the rate of vanillylamine conversion ( $1 \mathrm{U}=$ conversion of $1 \mu \mathrm{mol}$ vanillylamine per minute). Experiments were done at least in duplicates. The enzyme has a selectivity factor, E $>100$ which was calculated according to $E=\frac{\ln [(1-c) *(1-e e)]}{\ln [(1-c) *(1+e e)]}$, where $\mathrm{c}=$ conversion, ee $=$ enantiomeric excess).

\section{HPLC analysis}

Quantitative analysis of vanillin and vanillylamine were performed with a 1100 Series HPLC instrument (Agilent Technologies, Heilbronn, Germany) equipped with a quaternary pump, autosampler, diode array detector (DAD), fluorescence detector and a vacuum degasser. Chromatographic separation took place in a Zorbax SB-C18 $(2.1 \mathrm{~mm} \times 150 \mathrm{~mm} \times 3.5 \mu \mathrm{m})$ column (Agilent, USA). A gradient elution method was optimized using two mobile phases, A ( $0.5 \%$ formic acid in water) and B (0.5\% formic acid in methanol). The elution gradient started with an initial composition of $4 \% \mathrm{~B}$ and increased to 96\% B within 5 min. The late composition was kept isocratic for $7 \mathrm{~min}$, followed by returning back to initial composition in one minute. The method was ended with a 12 min equilibration step at the same composition resulting in a $25 \mathrm{~min}$ total runtime. Using the autosampler syringe, $5 \mu \mathrm{l}$ sample was injected to the column. The mobile phase flow rate kept constant at $0.2 \mathrm{ml} / \mathrm{min}$ while monitoring with DAD at $280 \mathrm{~nm}$ wavelength. Processing the HPLC data was done using Agilent Chemstation revision B.01.03 software.

$(R)$ - and (S)-1-phenylethylamine and acetophenone were determined using a Waters HPLC system (Binary HPLC pump 1525, UV/Vis detector 2489, Autosampler 2707) equipped with a Daicel ChiralCel OD-H column $(4.6 \times 25 \mathrm{~mm}, 5 \mu \mathrm{m})$. The mobile phase was $85: 15$ heptane/isopropanol with $0.1 \%$ butylamine and the flow rate was kept constant at $1 \mathrm{ml} / \mathrm{min}$ while monitoring at $210 \mathrm{~nm}$ wavelength. Using the autosampler syringe, $5 \mu \mathrm{l}$ sample was injected to the column. All sample analyses were performed at room temperature. Retention times: (R)-1-phenyethylamine: $5.6 \mathrm{~min}$; (S)-1-phenylethylamine: $6.8 \mathrm{~min}$; acetophenone: $4.6 \mathrm{~min}$.

\section{Competing interests}

The authors declare that they have no competing interests.

\section{Authors' contributions}

NW carried out the strain constructions, enzyme purification and characterisation, participated in the design of the study, and drafted the manuscript. Al performed the HPLC method optimisation. MGG participated in the design of the study and its coordination. MC conceived the study, and participated in its design and coordination and helped to draft the manuscript. All authors read and approved the final manuscript.

\section{Acknowledgements}

The Swedish Research Council FORMAS and The Royal Swedish Academy of Agriculture and Forestry are acknowledged for financial support. This research was also supported by BIOFLAVOUR, COST Action FA0907 (www.bioflavour.insa-toulouse.fr).

\section{Author details}

'Division of Applied Microbiology, Department of Chemistry, Lund University, SE-22100 Lund, Sweden. ${ }^{2}$ Centre for Analysis and Synthesis, Department of Chemistry, Lund University, SE-22100 Lund, Sweden.

Received: 9 August 2013 Accepted: 3 April 2014

Published: 9 April 2014

\section{References}

1. Luo XJ, Peng J, Li YJ: Recent advances in the study on capsaicinoids and capsinoids. Eur J Pharmacol 2011, 650:1-7.

2. Aza-Gonzalez C, Nunez-Palenius HG, Ochoa-Alejo N: Molecular biology of capsaicinoid biosynthesis in chili pepper (Capsicum spp.). Plant Cell Rep 2011, 30:695-706.

3. Yang D, Luo Z, Ma S, Wong WT, Ma L, Zhong J, He H, Zhao Z, Cao T, Yan Z, Liu D, Arendshorst WJ, Huang Y, Tepel M, Zhu Z: Activation of TRPV1 by dietary capsaicin improves endothelium-dependent vasorelaxation and prevents hypertension. Cell Metab 2010, 12:130-141.

4. Caterina MJ, Schumacher MA, Tominaga M, Rosen TA, Levine JD, Julius D: The capsaicin receptor: a heat-activated ion channel in the pain pathway. Nature 1997, 389:816-824.

5. Cortright DN, Szallasi A: Biochemical pharmacology of the vanilloid receptor TRPV1: an update. Eur J Biochem/FEBS 2004, 271:1814-1819.

6. Lang $Y$, Kisaka H, Sugiyama R, Nomura K, Morita A, Watanabe T, Tanaka $Y$, Yazawa S, Miwa T: Functional loss of pAMT results in biosynthesis of capsinoids, capsaicinoid analogs, in Capsicum annuum cv. CH-19 Sweet. Plant J 2009, 59:953-961.

7. Sutoh K, Kobata K, Yazawa S, Watanabe T: Capsinoid is biosynthesized from phenylalanine and valine in a non-pungent pepper, Capsicum annuum L. cv. CH-19 sweet. Biosci Biotechnol Biochem 2006, 70:1513-1516.

8. Gururaj HB, Padma MN, Giridhar P, Ravishankar GA: Functional validation of Capsicum frutescens aminotransferase gene involved in vanillylamine biosynthesis using Agrobacterium mediated genetic transformation studies in Nicotiana tabacum and Capsicum frutescens calli cultures. Plant Sci 2012, 195:96-105.

9. Mahnič M, Baebler S, Blejec A, Jalen S, Gruden K, Menart V, Jevševar S: Gene expression profiling of recombinant protein producing E. coli at suboptimal growth temperature. Acta Chim Slov 2012, 59:59-69.

10. Clark SM, Di Leo R, Dhanoa PK, Van Cauwenberghe OR, Mullen RT, Shelp BJ: Biochemical characterization, mitochondrial localization, expression, and potential functions for an Arabidopsis $\gamma$-aminobutyrate transaminase that utilizes both pyruvate and glyoxylate. J Exp Bot 2009, 60:1743-1757.

11. Clark SM, Di Leo R, Van Cauwenberghe OR, Mullen RT, Shelp BJ: Subcellular localization and expression of multiple tomato $\gamma$-aminobutyrate transaminases that utilize both pyruvate and glyoxylate. J Exp Bot 2009, 60:3255-3267.

12. Höhne M, Kühl S, Robins K, Bornscheuer UT: Efficient asymmetric synthesis of chiral amines by combining transaminase and pyruvate decarboxylase. Chem Bio Chem 2008, 9:363-365.

13. Kaulmann U, Smithies K, Smith MEB, Hailes HC, Ward JM: Substrate spectrum of $\omega$-transaminase from Chromobacterium violaceum DSM30191 and its potential for biocatalysis. Enzyme Microb Technol 2007, 41:628-637.

14. Koszelewski D, Tauber K, Faber K, Kroutil W: $\omega$-Transaminases for the synthesis of non-racemic a-chiral primary amines. Trends Biotechnol 2010, 6:324-332.

15. Trobacher CP, Clark SM, Bozzo GG, Mullen RT, DeEll JR, Shelp BJ: Catabolism of GABA in apple fruit: subcellular localization and biochemical characterization of two $\gamma$-aminobutyrate transaminases. Postharvest Biol Technol 2013, 75:106-113. 
16. Jankowski MD, Henry CS, Broadbelt LJ, Hatzimanikatis V: Group contribution method for thermodynamic analysis of complex metabolic networks. Biophys J 2008, 95:1487-1499.

17. Shin JS, Kim BG: Asymmetric synthesis of chiral amines with $\omega$-transaminase. Biotech Bioeng 1999, 65:206-211.

18. Truppo MD, Rozzell JD, Moore JC, Turner NJ: Rapid screening and scale-up of transaminase catalysed reactions. Org Biomol Chem 2009, 7:395-398.

19. Mutti FG, Fuchs CS, Pressnitz D, Sattler JH, Kroutil W: Stereoselectivity of four $(R)$-selective transaminases for the asymmetric amination of ketones. Adv Synth Catal 2011, 353:3227-3233.

20. Iwasaki A, Matsumoto K, Hasegawa J, Yasohara Y: A novel transaminase, (R)-amine:pyruvate aminotransferase, from Arthrobacter sp. KNK168 (FERM BP-5228): purification, characterization, and gene cloning. Appl Microbiol Biotechnol 2012, 93:1563-1573.

21. Schätzle S, Steffen-Munsberg F, Thontowi A, Höhne M, Robins K, Bornscheuer UT: Enzymatic asymmetric synthesis of enantiomerically pure aliphatic, aromatic and arylaliphatic amines with $(R)$-selective amine transaminases. Adv Synth Catal 2011, 353:2439-2445.

22. Hayaishi O, Nishizuka Y, Tatibana M, Takeshita M, Kuno S: Enzymatic studies on the metabolism of $\beta$-alanine. J Biol Chem 1961, 236:781-790.

23. Hwang BY, Ko SH, Park HY, Seo JH, Lee BS, Kim BG: Identification of $\omega$-aminotransferase from Caulobacter crescentus and site directed mutagenesis to broaden substrate specificity. J Microbiol Biotechnol 2008 18:48-54.

24. Kim KH: Purification and properties of amine a-ketogluterate transaminase from Escherichia coli. J Biol Chem 1964, 239:783-786.

25. Schätzle S, Höhne M, Redestad E, Robins K, Bornscheuer UT: Rapid and sensitive kinetic assay for characterization of $\omega$-transaminases. Anal Chem 2009, 81:8244-8248.

26. Shin JS, Yun H, Jang JW, Park I, Kim BG: Purification, characterization, and molecular cloning of a novel amine:pyruvate transaminase from Vibrio fluvialis JS17. Appl Microbiol Biotechnol 2003, 61:463-471.

27. Yun H, Lim S, Cho BK, Kim BG: $\omega$-Amino acid:pyruvate transaminase from Alcaligenes denitrificans $\mathrm{Y} 2 \mathrm{k}-2$ : a new catalyst for kinetic resolution of ß-amino acids and amines. Appl Environ Microbiol 2004, 70:2529-2534.

28. Sambrook J, Russell DW: Molecular cloning: a laboratory manual. New York, USA: Cold Spring Harbor Laboratory press; 2001.

29. Inoue H, Nojima H, Okayama H: High efficiency transformation of Escherichia coli with plasmids. Gene 1990, 96:23-28.

30. Ausubel F, Brent R, Kingston RE, Moore DD, Seidman JG, Smith JA, Struhl K: Short Protocols in Molecular Biology. New York, USA: John Wiley \& Sons; 1995.

31. Bradford MM: A rapid and sensitive method for the quantitation of microgram quantities of protein utilizing the principle of protein-dye binding. Anal Biochem 1976, 72:248-254.

doi:10.1186/1472-6750-14-25

Cite this article as: Weber et al: Biocatalytic potential of vanillin aminotransferase from Capsicum chinense. BMC Biotechnology 2014 14:25.

\section{Submit your next manuscript to BioMed Central and take full advantage of:}

- Convenient online submission

- Thorough peer review

- No space constraints or color figure charges

- Immediate publication on acceptance

- Inclusion in PubMed, CAS, Scopus and Google Scholar

- Research which is freely available for redistribution 